\title{
Are Rice and Spicy Diet Good for Functional Gastrointestinal Disorders?
}

\author{
Sutep Gonlachanvit, MD \\ Gastrointestinal Motility Research Unit, Division of Gastroenterology, Department of Internal Medicine, Faculty of Medicine, Chulalongkorn \\ University, Bangkok, Thailand
}

Rice- and chili-containing foods are common in Asia. Studies suggest that rice is completely absorbed in the small bowel, produces little intestinal gas and has a low allergenicity. Several clinical studies have demonstrated that rice-based meals are well tolerated and may improve gastrointestinal symptoms in functional gastrointestinal disorders (FGID). Chili is a spicy ingredient commonly use throughout Asia. The active component of chili is capsaicin. Capsaicin can mediate a painful, burning sensation in the human gut via the transient receptor potential vanilloid-1 (TRPV1). Recently, the TRPV1 expressing sensory fibers have been reported to increase in the gastrointestinal tract of patients with FGID and visceral hypersensitivity. Acute exposure to capsaicin or chili can aggravate abdominal pain and burning in dyspepsia and IBS patients. Whereas, chronic ingestion of natural capsaicin agonist or chili has been shown to decrease dyspeptic and gastroesophageal reflux disease (GERD) symptoms. The high prevalence of spicy food in Asia may modify gastrointestinal burning symptoms in patients with FGID. Studies in Asia demonstrated a low prevalence of heartburn symptoms in GERD patients in several Asian countries. In conclusion rice is well tolerated and should be advocated as the carbohydrate source of choice for patients with FGID. Although, acute chili ingestion can aggravate abdominal pain and burning symptoms in FGID, chronic ingestion of chili was found to improve functional dyspepsia and GERD symptoms in small randomized, controlled studies.

(J Neurogastroenterol Motil 2010;16:131-138)

Key Words

Chili pepper, Rice, Functional gastrointestinal disorder, Capsaicin, TRPV1 receptor

\section{Introduction}

Complaints of gastrointestinal symptoms after food ingestion are common in patients with functional gastrointestinal disorders (FGID) and are reported in 25-64\% of irritable bowel syndrome (IBS) patients. ${ }^{1,2}$ IBS patients often complain of food-related gastrointestinal symptoms secondary to more than one specific food.
A recent population-based study in the USA demonstrated that $16.5 \%$ and $28.3 \%$ of IBS patients had intolerance to $1-2$ food items and $>2$ items, respectively. ${ }^{2}$ These statistics suggest that hyper-sensitivity to the ingestion of foods is common in IBS. Research studies also demonstrate that certain foods, such as chili, fructose or fructan containing foods and fatty foods, can affect gastrointestinal motility and sensation ${ }^{3,4}$ and induce gastrointestinal symptoms more than other foods. ${ }^{4-6}$ This suggests that

Received: January 19th, 2010 Accepted: February 25th, 2010

(c) This is an Open Access article distributed under the terms of the Creative Commons Attribution Non-Commercial License (http://creativecommons. org/licenses/by-nc/3.0) which permits unrestricted non-commercial use, distribution, and reproduction in any medium, provided the original work is properly cited.

*Correspondence: Sutep Gonlachanvit, MD

Gastrointestinal Motility Research Unit, Division of Gastroenterology, Department of Internal Medicine, Faculty of Medicine,

Chulalongkorn University, Rama 4 Road, Pathumwan, Bangkok 10330, Thailand

Tel: +66-2-256-4265, Fax: +66-2-252-7839, E-mail: gsutep@hotmail.com

Financial support: This review was supported by the Ratchadapisek Sompotch Endowment Fund (GI Motility Research Unit grant).

Conflicts of interest: None. 
certain foods, and not just the process of eating foods, can aggravate symptoms in patients with FGID. Therefore, modification of either eating habits (reducing meal size and/or the time of meals) or the composition of meals (avoiding specific food items) may benefit patients with FGID, and studies on the effects of food on gastrointestinal functions and symptoms are important.

The effects of food ingestion on gastrointestinal symptoms in patients with FGID have been extensively studied, mainly in Western countries and with Western diets. Moreover, information regarding the effects of typical Asian foods on gastrointestinal symptoms of FGID is quite limited. This review will focus on the effects of specific but widely used Asian diets/ingredients, "rice and chili or spicy foods," on gastrointestinal functions and their roles on the symptoms of FGID.

\section{Characteristics of the Asian Diet}

The Asian diet is characterized by a high-carbohydrate, high-fiber, low-fat, and low-meat protein composition. ${ }^{7}$ Typical Asian food generally consists of rice and vegetables as the major source of carbohydrate and fiber. Vegetable oil is a common source of fat, whereas fish, eggs, poultry, and pork are the main sources of protein. This is in contrast to Western diets, which are rich in animal fat and beef protein but lower in carbohydrate and fiber contents. In addition, Asian foods often consist of several ingredients, such as chili, to make the foods tastier.

\section{Role of rice and high-carbohydrate diet in FGID}

In general, food can aggravate gastrointestinal symptoms by several mechanisms including: exaggerated physiologic responses of the gastrointestinal tract, food intolerance, allergy, increased intestinal gas, ${ }^{8}$ and modification of gut motility and sensation.

Food with high-carbohydrate content may cause symptoms of functional bowel disorders by both allergic and non-allergic mechanisms. As for the latter, carbohydrate may cause gastrointestinal symptoms because of incomplete absorption in the small bowel, such as lactose mal-absorption. ${ }^{9}$ In the allergic mechanism, the protein contents in the carbohydrate sources may cause allergic reactions to the gastrointestinal tract, such as gluten in wheat. ${ }^{10}$

Major types of carbohydrate in the human diet are: starches, sucrose, and lactose. They have to be digested into monosaccharide before being absorbed through the gut mucosa. If the complex-carbohydrate and monosaccharide are not completely absorbed into the small bowel, then these substances will enter the colon and will be fermented by colonic bacteria to produce gas and short-chain fatty acids, which may contribute to the symptoms reported in patients with FGID $^{11}$ such as diarrhea, gas, bloating, and abdominal discomfort and pain. The non-absorbable carbohydrates and their metabolites may induce gastrointestinal symptoms by their effects on gut sensation ${ }^{12}$ and gut motility, such as decreased gastric tone, decreased lower esophageal sphincter pressure and accelerated small bowel transit. ${ }^{13-15}$ A recent study in Asia (India) demonstrated that there is a similar prevalence of lactose intolerance in IBS patients and healthy controls. ${ }^{16}$ The authors performed lactose hydrogen breath tests in 124 IBS patients and 53 age- and gender-matched healthy controls. They found a similar prevalence of abnormal lactose hydrogen breath tests in IBS patients and healthy volunteers (72\% vs. $60 \%$ ). However, IBS patients developed gastrointestinal symptoms more often than healthy volunteers after ingestion of lactose (56\% vs. $34 \%) .{ }^{16}$ This higher rate of gastrointestinal symptoms suggests that there is a role of visceral hypersensitivity in the expression of carbohydrate mal-absorption symptoms and that the completeness of small intestinal absorption of carbohydrate is important in patients with IBS and can associate with their IBS symptoms.

\section{Rice is completely absorbed in the small intestine, producing little gas}

Major sources of complex carbohydrate or starch in the human diet are wheat, rice, oat, potato, and corn. The effects of each complex carbohydrate or starch on gastrointestinal symptoms depend on its fiber content, its allergenicity, and the completeness of the small bowel digestion and absorption. In Western countries, wheat is the major source of carbohydrate. It may cause gastrointestinal symptoms by allergic reaction to gluten, the major protein component of wheat. ${ }^{17,18}$ In a recent meta-analysis of 14 studies, patients who fulfill the criteria of IBS $(n=2,278)$ have a higher prevalence of celiac disease than controls $(n=1,926) .{ }^{19}$ The pooled prevalence of positive IgA-class antigliadin antibody, either positive endomysial antibody or tissue transglutaminase, and biopsy-proved celiac disease in IBS were $4.0 \%, 1.63 \%$, and $4.1 \%$, respectively. Pooled odds ratios ( $95 \%$ confidence interval) for positive IgA-class antigliadin antibody, either positive endomysial antibody or tissue transglutaminase, and biopsy-proved celiac disease in IBS patients compared with controls were 3.40 (1.62-7.13), 2.94 (1.36-6.35), and 4.34 (1.78-10.6), respec- 
tively. ${ }^{19}$ This implies that, in a subgroup of IBS patients, ingestion of a gluten-containing diet may aggravate and avoidance of the diet may improve gastrointestinal symptoms. ${ }^{20}$ Furthermore, wheat ingestion produces the highest peak of breath hydrogen compared to other sources of carbohydrate such as corn, oats, potatoes, beans, and rice in healthy humans. ${ }^{21}$ This suggests that wheat carbohydrate is not completely absorbed in the small bowel and that it may produce gastrointestinal symptoms, independent of gluten hypersensitivity. ${ }^{22}$

Rice is the major source of carbohydrate in Asian populations. In contrast to wheat and other sources of carbohydrate, rice is completely absorbed in the small bowel and produces very little intestinal gas after ingestion. ${ }^{21} \mathrm{~A}$ previous study demonstrated that the amount of hydrogen, a maker of carbohydrate metabolism by intestinal bacteria, ${ }^{23}$ in breath samples after rice ingestion is minimally increased and not significantly different from the fasting period. ${ }^{21}$ Furthermore, rice has been shown to have a low allergenicity. Previous studies demonstrated that serum IgG levels produced in reaction to several kinds of food such as wheat, beef, pork, lamb, soybean, shrimp, egg, and crab were increased in IBS patients compared to healthy humans, ${ }^{24,25}$ but the serum IgG levels produced to rice in IBS patients is mild ${ }^{26}$ or not increased. ${ }^{25,26}$ A study from China in 37 IBS, 28 functional dyspepsia, and 20 healthy controls demonstrated that serum IgG antibody titers to rice was similar in IBS $(28.7 \pm 0.5 \mathrm{U} / \mathrm{mL})$ and functional dyspepsia patients $(29.5 \pm 0.7 \mathrm{U} / \mathrm{mL})$ compared to healthy controls $(28.4 \pm 0.5 \mathrm{U} / \mathrm{mL})$. In contrast, the serum $\mathrm{IgG}$ antibody titer to wheat was increased in IBS patients $(60.6 \pm 3.4$ $\mathrm{U} / \mathrm{mL}$ ) compared to functional dyspepsia patients $(49.4 \pm 2.0$ $\mathrm{U} / \mathrm{mL})$ and healthy controls $(48.1 \pm 2.0 \mathrm{U} / \mathrm{mL}){ }^{25}$ This low production of IgG suggests that rice has a low allergenicity compared to other common foods.

\section{Rice has lowest fiber content compared to other common sources of carbohydrate}

It has been reported that fiber speeds up human gut transit ${ }^{27}$ and can improve constipation symptoms. ${ }^{28}$ However, its benefit in FGID is limited. Recent meta-analysis studies on the effect of fiber on global symptoms of IBS patients demonstrated conflicting results. ${ }^{28,29}$ In addition, it may worsen abdominal pain and bloating symptoms. ${ }^{28,29}$ In healthy humans, ingestion of fiber (psyllium) can delay intestinal gas transit and cause more gas retention after intestinal gas perfusion. ${ }^{30}$ Thus, a high-fiber diet may worsen abdominal bloating and pain by delaying intestinal gas transit and increasing gas production in the colon secondary to bacterial fermentation. In certain parts of Asia, such as in India, healthy controls and patients with IBS have more dietary fiber ( 51.7 and $52.3 \mathrm{~g} /$ day, respectively) than the recommended amount for the general population (20-40 g/day). ${ }^{31}$ Therefore, increasing the dietary fiber consumption of functional gastrointestinal disorder patients in certain parts of Asia may not provide any benefit but may worsen the bloating and abdominal pain symptoms.

Although the Asian diet is rich in fiber, rice - the widely used complex carbohydrate - has the lowest fiber content compared to other kinds of cereal. A previous study demonstrated that the total fiber content (insoluble + soluble fiber) of different kinds of cereal is lowest in rice and highest in wheat $(4.1 \%$ in rice vs. $12.5 \%$ in wheat). ${ }^{32}$ As high-fiber may worsen abdominal pain and bloating symptoms, rice may be the most preferable carbohydrate source for functional gastrointestinal disorder patients with predominant symptoms of bloating and abdominal pain.

\section{Clinical studies suggest benefits of rice-base meal in IBS}

Rice has been the major source of carbohydrate in exclusion diets in several clinical studies. ${ }^{33-37}$ These studies demonstrated that the exclusion diet is well tolerated and can improve IBS symptoms in both open and controlled studies. ${ }^{33-37}$ A recent study by King et al. ${ }^{38}$ suggests that the rice-based exclusion diet may improve symptoms in IBS by reducing intestinal gas production. The study was performed in 6 female IBS patients and 6 female controls by measuring 24-hour hydrogen and methane production after ingestion of rice-based exclusion diet or standard diet, in a crossover controlled trial, using a whole-body calorimeter. The authors found that after standard diet the gas excretion rate and hydrogen production was higher in IBS patients $(2.4 \mathrm{~mL} / \mathrm{min}$ and $332 \mathrm{~mL} / 24 \mathrm{hr}$, respectively) than in controls $(0.6 \mathrm{~mL} / \mathrm{min}$ and $162 \mathrm{~mL} / 24 \mathrm{hr})$. The rice-based exclusion diet reduced hydrogen production compared to standard diet in both IBS (79 vs. $332 \mathrm{~mL} / 24 \mathrm{hr}$ ) and controls (95 vs. $162 \mathrm{~mL} / 24$ $\mathrm{hr})$. In addition, in IBS patients, the exclusion diet reduced symptoms [symptom score $=8(5.25-10)$ vs. 4 (3-7)] and reduced the maximum gas excretion rate compared to the standard $\operatorname{diet}(0.5$ vs. $2.4 \mathrm{~mL} / \mathrm{min})$.

Recently, the very-low-carbohydrate strategy has been shown to improve IBS-D symptoms in a small open study. ${ }^{39}$ The authors found that 13 of the 17 patients who were enrolled completed the study. Ten (77\%) of the patients who completed the study reported adequate relief of IBS symptoms. Furthermore, 
the stool frequency, stool consistency, pain scores, and quality of life were significantly improved.

Because there have been reports of inadequate dietary intake because of food avoidance in IBS patients, the avoidance of poorly-absorbed carbohydrates combined with the consumption of well-absorbed carbohydrates or rice may be more appropriate than the use of very-low-carbohydrate diets in the dietary treatment strategy for IBS patients.

All together, rice may be the best source of carbohydrate for patients with functional bowel disorder because of its low allergenicity, its nearly complete absorption in the small bowel, and its low fiber content. In addition, a small crossover controlled study supports its benefit in IBS. ${ }^{38}$

\section{Effect of chili on FGID}

Chili and spicy food are common in most Asian countries. The average daily chili consumption in Asian people is 2.5-8 $\mathrm{g} /$ person. It is much higher than that of $0.05-0.5 \mathrm{~g} /$ person in European and American peoples. ${ }^{40}$ Recent studies suggest that acute and chronic ingestion of chili can modify gastrointestinal symptoms in FGID. ${ }^{6,41}$ Whether or not a high prevalence of spicy food modifies gastrointestinal symptoms at the population level is not known. In addition, data on the effect of chili or spicy foods on FGID in Asian countries with a high prevalence of spicy food have been limited.

\section{Capsaicin mediated visceral nociception in FGID}

The active ingredient of chili is capsaicin. Capsaicin can modulate gastrointestinal sensation via capsaicin or TRPV1 receptors. These receptors have been found at different levels throughout the gastrointestinal tract. ${ }^{42-50}$ Capsaicin, acid, and heat can stimulate the TRPV1 receptors and mediate a sensation of burning and pain. ${ }^{51}$ Several studies suggested that TRPV1 receptors can mediate sensations of warmth, pressure, cramping, and pain in the human gut. ${ }^{52}$ Increases in the number of TRPV1 receptors have been found in the gut mucosa of patients with conditions associated with visceral hypersensitivity, including in the esophagus of patients with non-erosive reflux disease (NERD), ${ }^{42}$ in the colon of patients with irritable bowel syndrome ${ }^{53}$ and in the rectum of patients with rectal hypersensitivity. ${ }^{43}$ Recent studies demonstrated that patients with FGID, including functional dyspepsia and irritable bowel syndrome, exhibit gut hypersensitivity to capsaicin or capsaicin containing chili. ${ }^{6,54}$ Hammer et al. ${ }^{54}$ studied the effect of $0.75 \mathrm{mg}$ capsaicin powder ingestion on gastrointestinal symptoms in 54 functional dyspepsia patients and 61 healthy controls. They found that after capsaicin ingestion, nausea, a flutter-like sensation, warmth and abdominal pain scores were higher in functional dyspepsia patients than in healthy volunteers. A recent study in 20 IBS-D patients demonstrated that ingestion of chili-containing meals produces higher abdominal pain and abdominal burning symptom scores than standard meals and when compared to the symptoms reported by healthy volunteers in response to ingestion of chili-containing meals. ${ }^{6}$ Studies suggest that abdominal pain and burning symptoms seem to be the typical gastrointestinal symptoms of capsaicin hypersensitivity, ${ }^{6,54}$ whereas abdominal bloating symptoms seems to be independent of the capsaicin pathways.

Low-grade inflammation in the gastrointestinal tract has been proposed as a major pathogenesis of FGID, especially in irritable bowel syndrome. ${ }^{55}$ Up-regulation of TRPV 1 pathways resulting in visceral hypersensitivity to mechanical and chemical stimulations has been reported following an induction of colonic inflammation in an animal model. ${ }^{56}$ In humans, gut inflammation has been reported to be associated with an increased number of TRPV1-expressing nerve fibers. ${ }^{50,57}$ Thus, hypersensitivity of the TRPV1 pathways in patients with FGID is likely a result of low-grade inflammation and may be an important pathogenesis of gut hypersensitivity, abdominal pain, and abdominal burning symptoms in FGID.

\section{Desensitization of capsaicin receptors, its role on patients' symptom profiles and treatment of FGID}

It has been reported that prior exposure of esophageal mucosa to capsaicin solution do not affect esophageal sensation in response to acid perfusion or to balloon distention. ${ }^{58}$ However, the study evaluated the effect of single stimulation of esophageal mucosa by perfusion of capsaicin solution into the esophagus and could not exclude the desensitization effects of capsaicin receptors in the gut mucosa after repeated exposure to capsaicin agonists.

It has been demonstrated that TRPV1 receptors can be desensitized by repeated exposure to capsaicin. ${ }^{48}$ Recent small studies suggested that chronic ingestion of capsaicin containing chili can modify dyspepsia symptoms in functional dyspepsia patients $^{41}$ and GERD symptoms in NERD ${ }^{59}$ by decreasing dyspeptic and GERD symptoms, respectively. Bortolotti et al. ${ }^{41}$ randomized 30 functional dyspepsia patients to receive $2.5 \mathrm{~g} /$ day of red pepper powder or placebo in a double-blind manner for 5 weeks. They found that red pepper significantly improved overall symptom scores, epigastric pain, fullness, and nausea scores rela- 
tive to placebo. The overall symptom scores decreased from 3.3 \pm 0.6 at baseline to $1.7 \pm 0.2$ at the end of week 5 for red chili treatment compared to from $3.4 \pm 0.7$ to $2.5 \pm 0.3$ for placebo treatment. In a preliminary study in 8 patients with NERD, red chili ingestion for 6 weeks significantly improved total GERD, heartburn, and regurgitation symptom scores compared to placebo. ${ }^{59}$ The authors found that, at baseline, total GERD scores, heartburn, and regurgitation scores were similar comparing between chili and placebo capsules (chili vs. placebo: $7.6 \pm$ 3.7 vs. $4.7 \pm 2.8,4.6 \pm 2.3$ vs. $3.2 \pm 2.1$, and $2.9 \pm 2.4$ vs. 1.5 \pm 1.6 , respectively). At the end of week 6 , red chili significantly decreased GERD symptom scores (chili vs. placebo: $0.9 \pm 1.2$ vs. $4.9 \pm 2.4)$, heartburn symptom scores $(0.4 \pm 0.6$ vs. $3.7 \pm$ 1.6), and food regurgitation symptom scores ( $0.5 \pm 0.8$ vs. $1.3 \pm$ 1.6) compared to placebo. The effects of chili ingestion on functional dyspepsia and GERD symptoms were observed after the 2nd week of treatment in both studies. The similar effects of chronic ingestion of red chili in functional dyspepsia and NERD patients suggests that capsaicin receptors play role on the development of both functional dyspepsia and NERD symptoms and is consistent with previous reports of visceral hypersensitivity to capsaicin in functional dyspepsia ${ }^{54}$ and increase TRPV1 receptors in NERD. ${ }^{42}$ In contrast, a previous study in 12 healthy volunteers reported that chronic chili ingestion induce more gastroesophageal refluxes. ${ }^{60}$ However, the duration of chili ingestions was too short ( $\leq 1$ week) in relative to the other studies, which showed the desensitization effect of chili (5-6 weeks). These limited data suggest that the natural capsaicin agonist (chili) may have a therapeutic role for pain and burning symp- toms in FGID and more research studies are needed to confirm this hypothesis.

The effect of spicy food, which is frequently eaten in Asia, on the gastrointestinal symptom profiles in FGID at population level is not clearly known. Studies of GERD symptoms in Asian patients have reported a lower prevalence of heartburn compared to Western patients. A study of GERD symptoms in German patients who underwent 24-hour esophageal $\mathrm{pH}$ monitoring showed that both heartburn and acid regurgitation are the main typical GERD symptoms, ${ }^{61}$ whereas a similar study in an Asian country (Thailand) with a high prevalence of spicy food reported only acid regurgitation, but not heartburn, as the main GERD symptom (Fig. 1). ${ }^{62}$ Furthermore, epidemiologic studies in Asian countries, including China, Iran, and Thailand, demonstrated lower heartburn/regurgitation symptom prevalence ratios $^{63-66}$ compared to Western or developed countries with a low prevalence of spicy food. ${ }^{67-69}$ However, the low heartburn/regurgitation symptom prevalence ratio was not observed in Korea. ${ }^{70}$ In Turkey, an European country with a high prevalence of spicy food, the prevalence of heartburn in the population is much lower than the prevalence of acid regurgitation (weekly heartburn vs. acid regurgitation: $10 \%$ vs. $15.6 \%$, respectively). ${ }^{71}$ When the studies that reported the prevalence of annual regurgitation and heartburn symptoms were included, studies of the American population reported a heartburn/regurgitation prevalence ratio of 0.91-0.94, ${ }^{68,69}$ whereas studies in China reported a lower ratio of $0.34{ }^{64}$ There has been no study that directly compares GERD symptom profiles between Asian and Western peoples or patients in the area of high and low prevalence of chili in the diet.
A

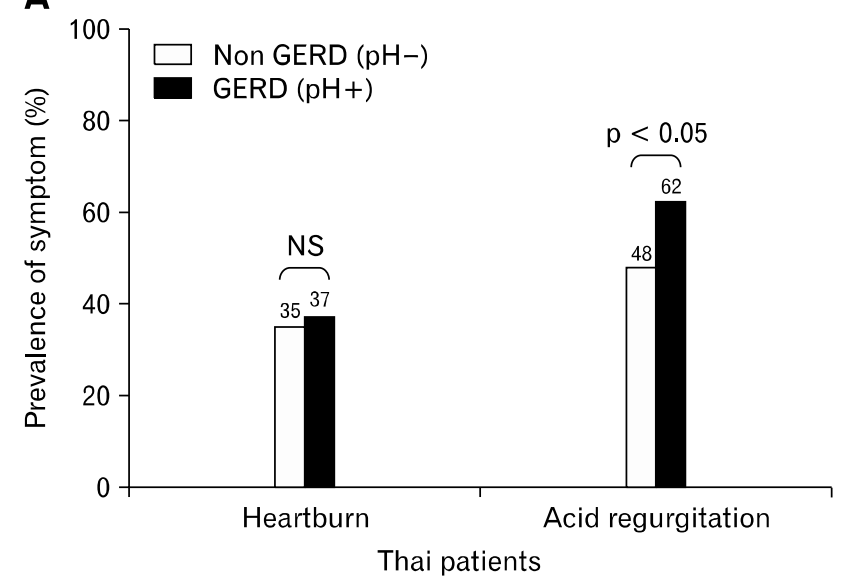

B

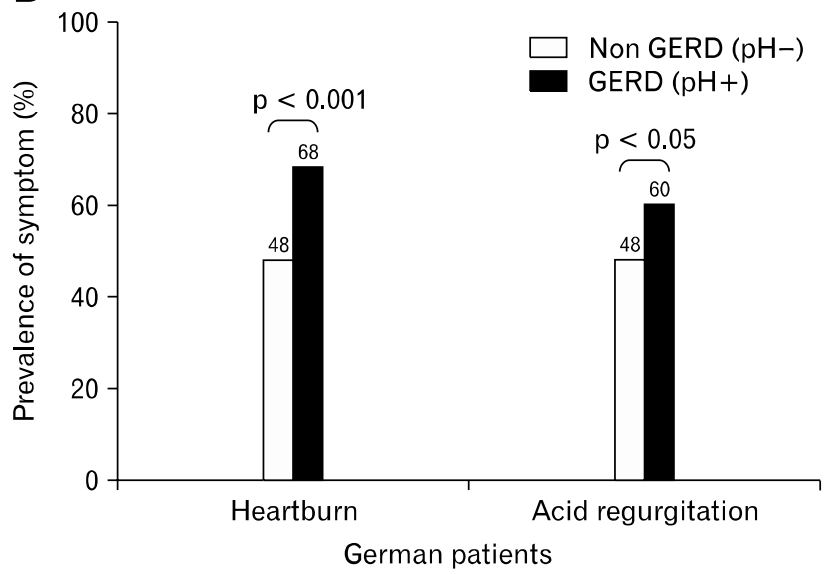

Figure 1. The prevalence of heartburn and acid regurgitation symptoms in patients with positive and negative 24-hour $\mathrm{pH}$ monitoring: a comparison of the 2 studies from Asia (A, Thailand) ${ }^{62}$ and Europe (B, German). ${ }^{61}$ 
However, the collective results of the available studies imply that acid or gastric content regurgitation into the esophagus in people in certain regions of Asia is not perceived as heartburn symptoms by the esophagus in the same way that heartburn symptoms are perceived by Western people. The high prevalence of spicy food may play a role in this finding, but this hypothesis has not been proven. The low prevalence of heartburn symptoms is not likely to be a misinterpretation of acid reflux symptoms in Thai people because acid perfusion tests produce no symptoms in most Thai GERD patients (GI Motility Research Unit, Chulalongkorn University, Thailand, un-published data). However, the heartburn/regurgitation symptom prevalence ratio is not lower in Mexico, where the prevalence of spicy food is high. This inconsistency suggests that not only spicy food, but also other factors, may influence the sensitivity of esophagus to gastro-esophageal reflux contents at the population level.

In summary, capsaicin or TRPV1 receptors are involved in the pathogenesis of burning and pain symptoms of the gastrointestinal tract. Recent small studies suggest that the chronic use of capsaicin-containing chili can decrease heartburn and abdominal pain in GERD and dyspepsia, respectively. In addition, the ratio of the prevalence of heartburn/regurgitation symptoms in the population is lower in several parts of Asia; this lower rate may be related to the high prevalence of chili or spicy food.

\section{Conclusion}

Rice seems to be the most preferable source of carbohydrate in patients with FGID. It has a low allergenicity and fiber content; it is also completely absorbed in the small bowel and produces little gas after ingestion. Therefore, it should be advocated as a major source of carbohydrate for patients with IBS and those with other functional GI disorders.

There has been increasing evidence to support the role of capsaicin receptors in the pathogenesis of symptoms of FGID. Preliminary studies support the role of desensitization of capsaicin receptors by chili, a natural capsaicin receptor agonist, for the treatment of functional dyspepsia and NERD. However, more research studies are needed to confirm this hypothesis.

\section{References}

1. Simrén M, Månsson A, Langkilde AM, et al. Food-related gastrointestinal symptoms in the irritable bowel syndrome. Digestion 2001;63:108-115.

2. Locke GR 3rd, Zinsmeister AR, Talley NJ, Fett SL, Melton LJ.
Risk factors for irritable bowel syndrome: role of analgesics and food sensitivities. Am J Gastroenterol 2000;95:157-165.

3. Rao SS, Kavelock R, Beaty J, Ackerson K, Stumbo P. Effects of fat and carbohydrate meals on colonic motor response. Gut 2000;46: 205-211.

4. Simrén M, Agerforz P, Björnsson ES, Abrahamsson H. Nutrientdependent enhancement of rectal sensitivity in irritable bowel syndrome (IBS). Neurogastroenterol Motil 2007;19:20-29.

5. Shepherd SJ, Parker FC, Muir JG, Gibson PR. Dietary triggers of abdominal symptoms in patients with irritable bowel syndrome: randomized placebo-controlled evidence. Clin Gastroenterol Hepatol 2008;6:765-771.

6. Gonlachanvit S, Mahayosnond A, Kullavanijaya P. Effects of chili on postprandial gastrointestinal symptoms in diarrhoea predominant irritable bowel syndrome: evidence for capsaicin-sensitive visceral nociception hypersensitivity. Neurogastroenterol Motil 2009;21:23-32.

7. Suhana N, Sutyarso, Moeloek N, Soeradi O, Sri Sukmaniah S, Supriatna J. The effects of feeding an Asian or Western diet on sperm numbers, sperm quality and serum hormone levels in cynomolgus monkeys (Macaca fascicularis) injected with testosterone enanthate (TE) plus depot medroxyprogesterone acetate (DMPA). Int J Androl 1999;22:102-112.

8. Floch MH, Narayan R. Diet in the irritable bowel syndrome. J Clin Gastroenterol 2002;35(suppl 1):S45-S52.

9. Beyerlein L, Pohl D, Delco F, Stutz B, Fried M, Tutuian R. Correlation between symptoms developed after the oral ingestion of $50 \mathrm{~g}$ lactose and results of hydrogen breath testing for lactose intolerance. Aliment Pharmacol Ther 2008;27:659-665.

10. Frazer AC, Fletcher RF, Ross CA, Shaw B, Sammons HG, Schneider R. Gluten-induced enteropathy: the effect of partially digested gluten. Lancet 1959;2:252-255.

11. Goldstein R, Braverman D, Stankiewicz H. Carbohydrate malabsorption and the effect of dietary restriction on symptoms of irritable bowel syndrome and functional bowel complaints. Isr Med Assoc J 2000;2:583-587.

12. Cherbut C. Motor effects of short-chain fatty acids and lactate in the gastrointestinal tract. Proc Nutr Soc 2003;62:95-99.

13. Madsen JL, Linnet J, Rumessen JJ. Effect of nonabsorbed amounts of a fructose-sorbitol mixture on small intestinal transit in healthy volunteers. Dig Dis Sci 2006;51:147-153.

14. Ropert A, Cherbut C, Rozé C, et al. Colonic fermentation and proximal gastric tone in humans. Gastroenterology 1996;111:289-296.

15. Piche T, Zerbib F, Varannes SB, et al. Modulation by colonic fermentation of LES function in humans. Am J Physiol Gastrointest Liver Physiol 2000;278:G578-G584.

16. Gupta D, Ghoshal UC, Misra A, Misra A, Choudhuri G, Singh K. Lactose intolerance in patients with irritable bowel syndrome from northern India: a case-control study. J Gastroenterol Hepatol 2007; 22:2261-2265.

17. Ciclitira PJ, King AL, Fraser JS. AGA technical review on celiac sprue. American Gastroenterological Association. Gastroenterology 2001;120:1526-1540.

18. Dicke WK, Weijers HA, van de Kamer JH. Coeliac disease. The presence in wheat of a factor having a deleterious effect in cases of coeliac disease. Acta Paediatr 1953;42:34-42.

19. Ford AC, Chey WD, Talley NJ, Malhotra A, Spiegel BM, 
Moayyedi P. Yield of diagnostic tests for celiac disease in individuals with symptoms suggestive of irritable bowel syndrome: systematic review and meta-analysis. Arch Intern Med 2009;169:651-658.

20. Wahnschaffe U, Schulzke JD, Zeitz M, Ullrich R. Predictors of clinical response to gluten-free diet in patients diagnosed with diarrhea-predominant irritable bowel syndrome. Clin Gastroenterol Hepatol 2007;5:844-850.

21. Levitt MD, Hirsh P, Fetzer CA, Sheahan M, Levine AS. H2 excretion after ingestion of complex carbohydrates. Gastroenterology 1987;92:383-389.

22. Tursi A, Brandimarte G. The symptomatic and histologic response to a gluten-free diet in patients with borderline enteropathy. J Clin Gastroenterol 2003;36:13-17.

23. Park H. The role of small intestinal bacterial overgrowth in the pathophysiology of irritable bowel syndrome. J Neurogastroenterol Motil 2010;16:3-4.

24. Zar S, Benson MJ, Kumar D. Food-specific serum IgG4 and IgE titers to common food antigens in irritable bowel syndrome. Am J Gastroenterol 2005;100:1550-1557.

25. Zuo XL, Li YQ, Li WJ, et al. Alterations of food antigen-specific serum immunoglobulins $\mathrm{G}$ and $\mathrm{E}$ antibodies in patients with irritable bowel syndrome and functional dyspepsia. Clin Exp Allergy 2007;37:823-830.

26. Zar S, Mincher L, Benson MJ, Kumar D. Food-specific IgG4 antibody-guided exclusion diet improves symptoms and rectal compliance in irritable bowel syndrome. Scand J Gastroenterol 2005; 40:800-807.

27. Harvey RF, Pomare EW, Heaton KW. Effects of increased dietary fibre on intestinal transit. Lancet 1973;1:1278-1280.

28. Bijkerk CJ, Muris JW, Knottnerus JA, Hoes AW, de Wit NJ. Systematic review: the role of different types of fibre in the treatment of irritable bowel syndrome. Aliment Pharmacol Ther 2004;19: 245-251.

29. Quartero AO, Meineche-Schmidt V, Muris J, Rubin G, de Wit N. Bulking agents, antispasmodic and antidepressant medication for the treatment of irritable bowel syndrome. Cochrane Database Syst Rev 2005;(2):CD003460.

30. Gonlachanvit S, Coleski R, Owyang C, Hasler W. Inhibitory actions of a high fibre diet on intestinal gas transit in healthy volunteers. Gut 2004;53:1577-1582.

31. Singh N, Makharia GK, Joshi YK. Dietary survey and total dietary fiber intake in patients with irritable bowel syndrome attending a tertiary referral hospital. Indian J Gastroenterol 2008;27:66-70.

32. Ramulu P, Rao PU. Effect of processing on dietary fiber content of cereals and pulses. Plant Foods Hum Nutr 1997;50:249-257.

33. Bentley SJ, Pearson DJ, Rix KJ. Food hypersensitivity in irritable bowel syndrome. Lancet 1983;2:295-297.

34. Farah DA, Calder I, Benson L, MacKenzie JF. Specific food intolerance: its place as a cause of gastrointestinal symptoms. Gut 1985; 26:164-168.

35. Nanda R, James R, Smith H, Dudley CR, Jewell DP. Food intolerance and the irritable bowel syndrome. Gut 1989;30:1099-1104.

36. Burden S. Dietary treatment of irritable bowel syndrome: current evidence and guidelines for future practice. J Hum Nutr Diet 2001;14:231-241.

37. McKee AM, Prior A, Whorwell PJ. Exclusion diets in irritable bow- el syndrome: are they worthwhile? J Clin Gastroenterol 1987;9: 526-528.

38. King TS, Elia M, Hunter JO. Abnormal colonic fermentation in irritable bowel syndrome. Lancet 1998;352:1187-1189.

39. Austin GL, Dalton CB, Hu Y, et al. A very low-carbohydrate diet improves symptoms and quality of life in diarrhea-predominant irritable bowel syndrome. Clin Gastroenterol Hepatol 2009;7:706-708.

40. Govindarajan VS, Sathyanarayana MN. Capsicum-production, technology, chemistry, and quality. Part V. Impact on physiology, pharmacology, nutrition, and metabolism; structure, pungency, pain, and desensitization sequences. Crit Rev Food Sci Nutr 1991;29: 435-474.

41. Bortolotti M, Coccia G, Grossi G, Miglioli M. The treatment of functional dyspepsia with red pepper. Aliment Pharmacol Ther 2002;16:1075-1082.

42. Bhat YM, Bielefeldt K. Capsaicin receptor (TRPV1) and non-erosive reflux disease. Eur J Gastroenterol Hepatol 2006;18:263-270.

43. Chan CL, Facer P, Davis JB, et al. Sensory fibres expressing capsaicin receptor TRPV1 in patients with rectal hypersensitivity and faecal urgency. Lancet 2003;361:385-391.

44. Dömötör A, Kereskay L, Szekeres G, Hunyady B, Szolcsányi J, Mózsik G. Participation of capsaicin-sensitive afferent nerves in the gastric mucosa of patients with Helicobacter pylori-positive or-negative chronic gastritis. Dig Dis Sci 2007;52:411-417.

45. Facer P, Knowles CH, Tam PK, et al. Novel capsaicin (VR1) and purinergic (P2X3) receptors in Hirschsprung's intestine. J Pediatr Surg 2001;36:1679-1684.

46. Faussone-Pellegrini MS, Taddei A, Bizzoco E, Lazzeri M, Vannucchi MG, Bechi P. Distribution of the vanilloid (capsaicin) receptor type 1 in the human stomach. Histochem Cell Biol 2005; 124:61-68.

47. Green BG, Hayes JE. Capsaicin as a probe of the relationship between bitter taste and chemesthesis. Physiol Behav 2003;79:811-821.

48. Karrer T, Bartoshuk L. Effects of capsaicin desensitization on taste in humans. Physiol Behav 1995;57:421-429.

49. Liu L, Simon SA. Acidic stimuli activates two distinct pathways in taste receptor cells from rat fungiform papillae. Brain Res 2001; 923:58-70.

50. Matthews PJ, Aziz Q, Facer P, Davis JB, Thompson DG, Anand P. Increased capsaicin receptor TRPV1 nerve fibres in the inflamed human oesophagus. Eur J Gastroenterol Hepatol 2004;16:897-902.

51. Caterina MJ, Schumacher MA, Tominaga M, Rosen TA, Levine JD, Julius D. The capsaicin receptor: a heat-activated ion channel in the pain pathway. Nature 1997;389:816-824.

52. Schmidt B, Hammer J, Holzer P, Hammer HF. Chemical nociception in the jejunum induced by capsaicin. Gut 2004;53:11091116.

53. Akbar A, Yiangou Y, Facer P, Walters JR, Anand P, Ghosh S. Increased capsaicin receptor TRPV1 expressing sensory fibres in irritable bowel syndrome and their correlation with abdominal pain. Gut 2008;57:923-929.

54. Hammer J, Führer M, Pipal L, Matiasek J. Hypersensitivity for capsaicin in patients with functional dyspepsia. Neurogastroenterol Motil 2008;20:125-133.

55. Barbara G, De Giorgio R, Stanghellini V, Cremon C, Corinaldesi R. A role for inflammation in irritable bowel syndrome? Gut 2002; 
51(suppl 1):i41-i44.

56. Miranda A, Nordstrom E, Mannem A, Smith C, Banerjee B, Sengupta JN. The role of transient receptor potential vanilloid 1 in mechanical and chemical visceral hyperalgesia following experimental colitis. Neuroscience 2007;148:1021-1032.

57. Yiangou Y, Facer P, Dyer NH, et al. Vanilloid receptor 1 immunoreactivity in inflamed human bowel. Lancet 2001;357:1338-1339.

58. Kindt S, Vos R, Blondeau K, Tack J. Influence of intra-oesophageal capsaicin instillation on heartburn induction and oesophageal sensitivity in man. Neurogastroenterol Motil 2009;21:1032-e82.

59. Jutaghokiat S, Imraporn B, Gonlachanvit S. Chili improves gastroesophageal reflux symptoms in patients with non erosive gastroesophageal reflux disease (NERD) [abstract]. Gastroenterology 2009;136(suppl 1):A92.

60. Milke P, Diaz A, Valdovinos MA, Moran S. Gastroesophageal reflux in healthy subjects induced by two different species of chilli (Capsicum annum). Dig Dis 2006;24:184-188.

61. Klauser AG, Schindlbeck NE, Muller-Lissner SA. Symptoms in gastro-oesophageal reflux disease. Lancet 1990;335:205-208.

62. Gonlachanvit S, Sumdin P. Relationship between upper gastrointestinal symptoms and positive $24 \mathrm{hr}$ esophageal $\mathrm{pH}$ tests in Thai patients with chronic upper gastrointestinal symptoms [abstract]. Neurogastroenterol Motil 2006;18:708.

63. Ma XQ, Cao Y, Wang R, et al. Prevalence of, and factors associated with, gastroesophageal reflux disease: a population-based study in Shanghai, China. Dis Esophagus 2009;22:317-322.

64. Wong WM, Lai KC, Lam KF, et al. Prevalence, clinical spectrum and health care utilization of gastro-oesophageal reflux disease in a Chinese population: a population-based study. Aliment Pharmacol Ther 2003;18:595-604.

65. Nouraie M, Razjouyan H, Assady M, Malekzadeh R, NasseriMoghaddam S. Epidemiology of gastroesophageal reflux symptoms in Tehran, Iran: a population-based telephone survey. Arch Iran Med 2007;10:289-294.

66. Chen M, Xiong L, Chen H, Xu A, He L, Hu P. Prevalence, risk factors and impact of gastroesophageal reflux disease symptoms: a population-based study in South China. Scand J Gastroenterol 2005;40:759-767.

67. Eslick GD, Talley NJ. Gastroesophageal reflux disease (GERD): risk factors, and impact on quality of life-a population-based study. J Clin Gastroenterol 2009;43:111-117.

68. Locke GR 3rd, Talley NJ, Fett SL, Zinsmeister AR, Melton LJ 3rd. Prevalence and clinical spectrum of gastroesophageal reflux: a population-based study in Olmsted County, Minnesota. Gastroenterology 1997;112:1448-1456.

69. Locke GR 3rd, Talley NJ, Fett SL, Zinsmeister AR, Melton LJ 3rd. Risk factors associated with symptoms of gastroesophageal reflux. Am J Med 1999;106:642-649.

70. Yang SY, Lee OY, Bak YT, et al. Prevalence of gastroesophageal reflux disease symptoms and uninvestigated dyspepsia in Korea: a population-based study. Dig Dis Sci 2008;53:188-193.

71. Kitapçioğlu G, Mandiracioğlu A, Caymaz Bor C, Bor S. Overlap of symptoms of dyspepsia and gastroesophageal reflux in the community. Turk J Gastroenterol 2007;18:14-19. 